\title{
RIMAPS and Variogram Characterization of Soil Microstructure Patterns
}

\author{
Eduardo A. Favret ${ }^{1,2}$, Néstor O. Fuentes ${ }^{2,3}$, and Héctor J. M. Morrás ${ }^{1}$ \\ ${ }^{1}$ Instituto Nacional de Tecnología Agropecuaria (INTA), Instituto de Suelos. De las Cabañas y los \\ Reseros s/n. B1712WAA. Castelar. Buenos Aires. Argentina. \\ ${ }^{2}$ Instituto de Tecnología "Prof. Jorge A. Sábato", Universidad Nacional de Gral. San Martín. Av. \\ Gral. Paz 1499. B1650KNA. San Martín. Buenos Aires. Argentina. \\ ${ }^{3}$ Comisión Nacional de Energía Atómica (CNEA), CAC, U. A. Materiales. Av. Gral. Paz 1499. \\ B1650KNA. San Martín. Buenos Aires. Argentina.
}

This research work introduces the application of Rotated Image with Maximum Average Power Spectrum (RIMAPS) and Variogram on micromorphological studies of soil samples [1] [2] [3]. This kind of analysis allows finding the preferential directions, determined by RIMAPS, of the soil microstructure pattern according to different scale lengths (SL), and calculated by Variogram. The soil sample studied corresponds to the A surface horizon of a Typic Hapludoll from the Pampean region of Argentina. A thin section of the soil was observed by transmission polarizing light microscopy [4]. It can be seen in figure 1 (negative image of the original obtained with plain polarized light) the typical microstructure, which consists on voids (black objects) and groundmass. The voids, constituted mainly of cavities, planes and some vesicles, seem to be orderly distributed. The RIMAPS spectrum of the original image (Fig.2) shows an absolute maximum around $20^{\circ}$, in concordance with the preferential direction of the voids distribution. There is an absolute minimum around $95^{\circ}$, and the curve increases towards $0^{\circ}$ and $180^{\circ}$. There are also secondary maxima indicating that other arrangements of voids and groundmass are present. The Variogram method, illustrated in Fig. 3, gives the typical lengths of the soil microstructure. The four main SL obtained are $0.25 \mathrm{~mm}, 0.40 \mathrm{~mm}, 0.60 \mathrm{~mm}$ and $1.50 \mathrm{~mm}$. These values correspond to the lengths of the cavities or planes, the separation between planes, the diameter of vesicles, etc. Therefore, with the systematic use of both techniques, angular directions and dimensions of the pattern can be found. The following step was to filter the original image with the four SL previously found with Variogram, then obtain the respective waviness images (an example is included in Figs.4 and 5), and finally analyze them with RIMAPS (see Fig.6). The idea was to determine the voids pattern according to their dimensions. We eliminated the small characteristics of the soil microstructure progressively. It is clearly seen that the RIMAPS spectrum of the waviness image with $0.25 \mathrm{~mm}$ of cut-off length, is more similar to the RIMAPS spectrum of the original image, than the RIMAPS spectrum of the waviness image with $1.50 \mathrm{~mm}$ of cut-off. The maxima found around $0^{\circ}\left(180^{\circ}\right), 60^{\circ}$ and $90^{\circ}$ of the latter, are due to the main directions of the biggest voids and their arrangement. It can be concluded that the combined use of RIMAPS and Variogram may provide a new tool to describe the microstructure patterns and characterize the micromorphology of soils.

References

[1] N. O. Fuentes and E. A. Favret, Journal of Microscopy. 206 (2002) 72-83.

[2] E. A. Favret et al., Applied Surface Science. 230 (2004) 60-72.

[3] E. A. Favret and N. O. Fuentes, Microscopy Today. 12 (2004) 24-26.

[4] G. Stoops, Guidelines for Analysis and Description of Soil and Regolith Thin Sections, 1st ed., Soil Science Society of America, Madison, USA, 2003. pp 1-184. 


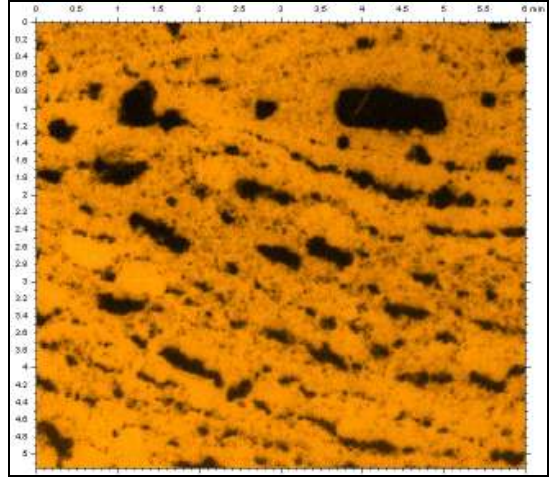

Figure 1: Negative image of the soil sample

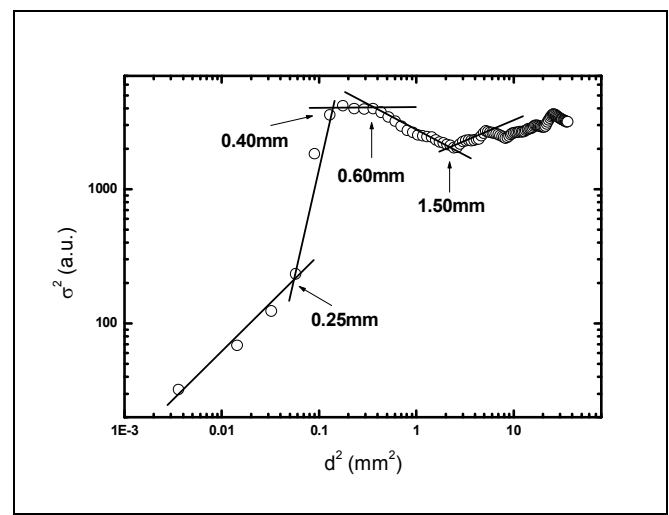

Figure 3: Variogram of fig.1. Scale lengths are indicated.

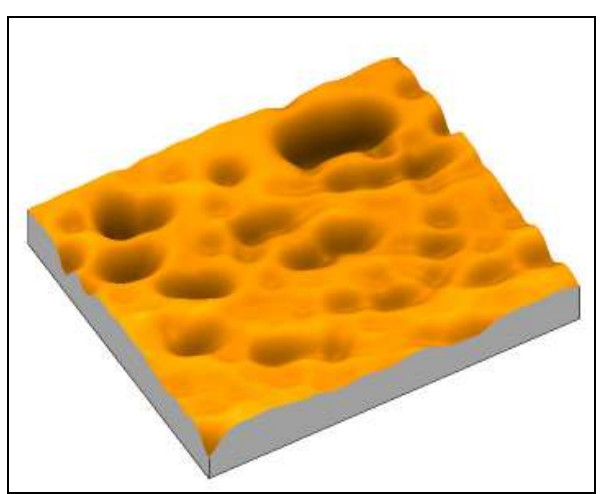

Figure 5: Three dimensional image of fig. 4

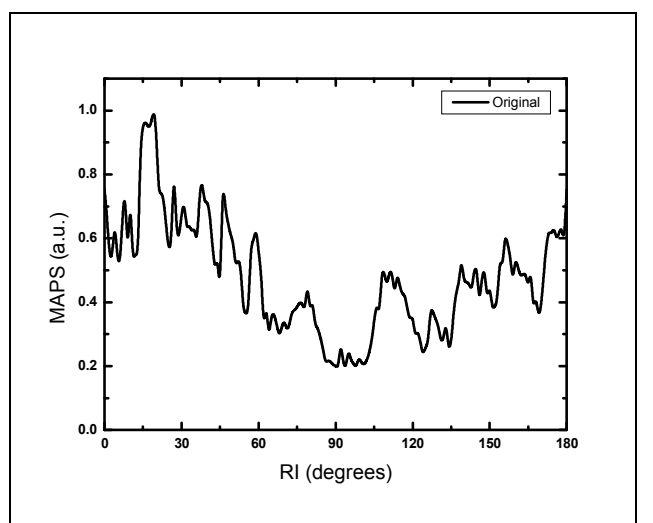

Figure 2: RIMAPS spectrum of fig. 1

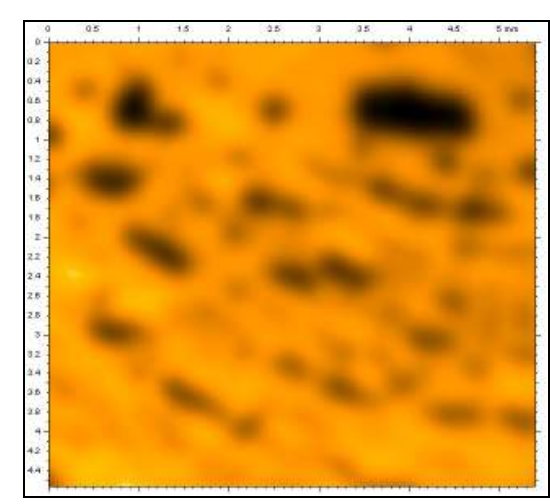

Figure 4: Waviness image of fig. 1 with $0.60 \mathrm{~mm}$ of cut-off length.

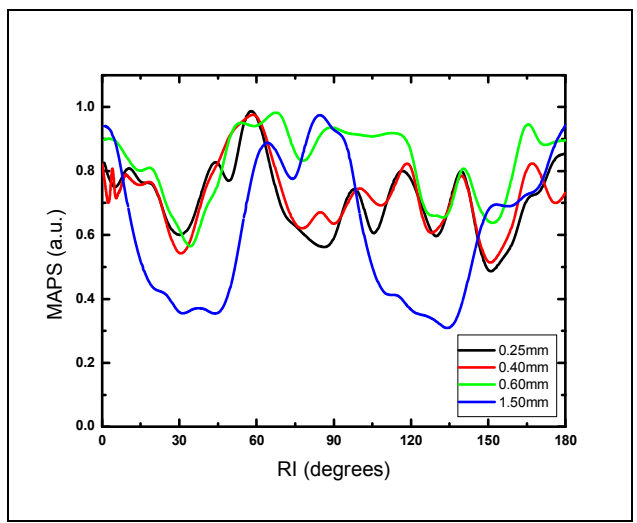

Figure 6: RIMAPS spectra of different waviness images obtained from fig. 1. 